\title{
Molecular structure of phosphabenzene: Analysis combining electron diffraction and microwave data
}

\author{
T. C. Wong and L. S. Bartell \\ Department of Chemistry, University of Michigan, Ann Arbor, Michigan 48104 \\ (Received 20 May 1974)

\begin{abstract}
The average ( $r_{a}$ ) structure of vapor phase $\mathrm{C}_{5} \mathrm{H}_{5} \mathrm{P}$, the phosphorus congener of pyridine, was deduced. Vibrational corrections of diffraction data and rotational constants were made via a normal coordinate analysis based on an approximate quadratic force field. The heterocyclic molecule was found to be planar with principal structure parameters and uncertainties $(2.5 \sigma)$ of $r_{g}(\mathrm{C}-\mathrm{P})=1.733 \pm 0.003 \AA, r_{g}\left(\mathrm{C}_{2}-\mathrm{C}_{3}\right)=1.413 \pm 0.010 \AA, r_{g}\left(\mathrm{C}_{3}-\mathrm{C}_{4}\right)=1.384 \pm 0.012 \AA$, $r_{g}(\mathrm{C}-\mathrm{H})=1.122 \pm 0.015 \AA . \AA \mathrm{CPC}=101.1^{\circ} \pm 0.3^{\circ}, \quad \Varangle \mathrm{PCC}=124.4^{\circ}+0.7^{\circ}, \quad$ and $\Varangle \mathrm{C}_{2} \mathrm{C}_{3} \mathrm{C}_{4}=123.7^{\circ} \pm 0.8^{\circ}$. Amplitudes of vibration were determined in the diffraction analysis as well as in the normal coordinate computation. A variety of different types of error matrices were computed to assess the effect of data correlations and the possible coupling, over and above scale factor shifts, between systematic errors in intensities and derived parameters. Conventional treatments of data correlations appear to lead to overoptimistic error estimates in the case of the longer internuclear distances. The structural characteristics of phosphabenzene are those expected for an aromatic molecule. Semiempirical molecular orbital calculations, adjusted to fit the experimental structure,
\end{abstract} \\ suggest a small but significant involvement of phosphorus $d$ orbitals in the $\pi$ bonding.
}

\section{INTRODUCTION}

Benzene and pyridine are two of the best known compounds in chemistry. Their properties and the properties of their derivatives have been the prime empirical evidence guiding the formulation of theories of aromaticity and $\pi$ bonding. Yet, compounds similar to pyridine with other heteroatoms had not been known to exist until quite recently. Therefore, when the congeners of pyridine, phosphabenzene (phosphorin), and arsabenzene (arsenin) were synthesized in $1971,{ }^{1}$ it became of interest to study their structures in order to infer, insofar as possible, the degree of aromaticity and the participation of the $d$ orbitals of the heteroatom in the bonding.

Phosphabenzene is particularly interesting, because it has been shown that a number of compounds as well as ligands can be derived from it. Even before the unsubstituted phosphabenzene was synthesized, Schweig et $a l .^{2}$ studied its electronic structure by the CNDO/2 molecular orbital method using a hypothetical geometry. Later, its structure was studied by Kuczkowski and Ashe $^{3}$ using microwave spectroscopy, but owing to the lack of sufficient isotopic species, it was possible only to guess a set of plausible structural parameters from the experimental data. However, various substituted phosphabenzenes and $\lambda^{5}$-phosphabenzenes (involving pentavalent phosphorus) were studied, primarily by $\mathrm{x}$-ray diffraction. ${ }^{4}$ These studies showed that the phosphabenzene ring was planar. Although the experimental information from the microwave spectroscopic study was not enough to solve the structure of phosphabenzene, incorporation of microwave rotational constants into an electron diffraction analysis should give a resulting structure more precise than that yielded by the latter method alone.

Therefore the scope of this research is to study the structure of phosphabenzene in the gas phase by electron diffraction and also by a combined analysis using both electron diffraction and microwave spectroscopic data. The merits of a combined analysis using data from sev- eral sources in the determination of molecular structure will be evaluated.

\section{EXPERIMENTAL PROCEDURE}

The sample of phosphabenzene was obtained from Professor Arthur Ashe and Dr. Thomas Schmidt of the University of Michigan. It was purified by vacuum distillation. When examined by infrared spectroscopy no impurity was detected. The sample was then used without further treatment.

Diffraction patterns were record on $4 \times 5$ in. Kodak electron image plates using the electron diffraction unit of the University of Michigan, ${ }^{5}$ at the $21 \mathrm{~cm}$ camera distance with $r^{2}$ and $r^{3}$ sectors, and at the $11 \mathrm{~cm}$ camera distance with an $r^{3}$ sector. The $40 \mathrm{kV}$ incident electrons were used. Detailed experimental conditions are given in Table I.

Plates were developed at $68^{\circ} \mathrm{F}$ for 3 min with Kodak HRP developer. Absorbances, measured with an automatic recording microphotometer with digital output, ${ }^{6}$ were converted to exposures, correcting for the nonlinear response of the photographic emulsion, by the equation, ${ }^{7}$

$$
E=A\left(1+0.1 A+0.0133 A^{2}+0.002 A^{3}\right),
$$

where $A$ and $E$ are the absorbance and the corresponding exposure, respectively. Five plates from each camera geometry were selected for analyses.

\section{ANALYSIS OF DATA}

Experimental intensities were obtained by averaging the data from plates selected from each camera geometry. Flat plate corrections and corrections for sector irregularities and extraneous scattering were made before intensities were leveled in the usual way. ${ }^{8}$ Tabulated atomic elastic and inelastic scattering factors of Schäfer, Yates, and Bonham ${ }^{9}$ were used throughout the analysis. 
Molecular parameters were refined by comparing experimental and calculated reduced molecular intensities $M(s)$, where

$$
M(s)=I_{0}(s) / I_{b}(s)-1
$$

by a least squares procedure. Initially, intensity data from each camera geometry were treated separately. After the background function $I_{b}(s)$ for the separate camera geometries had been refined and established using the usual criteria, ${ }^{10}$ a blended experimental $M(s)$ was constructed by merging data from the three camera geometries to span a range of $s=2.8-38.0 \AA^{-1}$. The experimental leveled intensities and background functions for all camera geometries are available from ASIS. ${ }^{11}$ The indices of resolutions were found to be $0.917,0.833$, and 1.041 for the $21 \mathrm{~cm} r^{2}$ sector, $21 \mathrm{~cm} r^{3}$ sector, and $11 \mathrm{~cm} r^{3}$ sector camera geometries, respectively.

A radial distribution function was calculated using a damping factor of $\exp \left(-0.0021 \mathrm{~s}^{2}\right)$, with the usual correction for scattering by planetary electrons ${ }^{12}$ and integral termination errors. ${ }^{13}$ Anharmonicity constants ${ }^{14}$ for all bonded distances were estimated from the empirical relations of Herschbach and Laurie, ${ }^{15}$ and in this case, they were estimated to be $1.7 \AA^{-1}$ for $C-P$ bonds, $1.9 \AA^{-1}$ for $\mathrm{C}-\mathrm{C}$ bonds, and $2.1 \AA^{-1}$ for $\mathrm{C}-\mathrm{H}$ bonds. For all nonbonded distances they were taken to equal $2.0 \AA^{-1}$. The molecular model for the analysis using only diffraction data was based on $r_{g}$ lengths for all bonded distances and $r_{g}$ lengths minus shrinkage corrections for nonbonded distances, and the angles were considered to be nearly equal to those in the $r_{\alpha}$ structure. Shrinkage ${ }^{16}$ for all nonbonded distances were estimated from an approximate force field, the details of which are to be discussed below, and from comparison with those of benzene ${ }^{17}$ and pyridine. ${ }^{18}$ They are listed in Table $I$. However, in the analysis combining diffraction and microwave spectroscopic data, the $r_{z}$ (or $r_{\alpha}^{0}$ ) structure was used to construct the model to avoid the inconsistency arising in certain cyclic structures where $r_{g}$ bond lengths are incompatible with $r_{\alpha}$ angles in a closed ring.

Several assumptions were made prior to the least squares analysis to reduce the number of parameters. The numbering of atoms corresponds to that in Fig. 1.

(1) The molecule was assumed to be planar (the va-

TABLE I. Experimental conditions under which diffraction plates of phosphabenzene were recorded.

\begin{tabular}{|c|c|c|c|}
\hline & \multicolumn{3}{|c|}{ Camera geometry } \\
\hline & I & II & III \\
\hline Camera distance $(\mathrm{cm})$ & 21.405 & 21.029 & 11.133 \\
\hline Sector (sector radius, $\mathrm{cm}$ ) & $r^{2}(2.5)$ & $r^{3}(4.4)$ & $r^{3}(4.4)$ \\
\hline Nozzle temperature $\left({ }^{\circ} \mathrm{C}\right)$ & 29 & 29 & 29 \\
\hline Sample pressure ${ }^{2}$ (torr) & $5-10$ & $5-10$ & $5-10$ \\
\hline Exposure time (sec) & $1-2$ & $7-12$ & $21-30$ \\
\hline Beam current $\left(\mu_{\mathrm{A}}\right)$ & 0.52 & 0.52 & 0.52 \\
\hline Diameter of Pt nozzle $(\mathrm{cm})$ & 0.030 & 0.030 & 0.030 \\
\hline
\end{tabular}

aThe vapor pressure of phosphabenzene has not been reported in the literature. Its boiling point is expected to be in the range of about $120-160^{\circ} \mathrm{C}$. The values listed in the table were roughly estimated by Trouton's rule.
TABLE II. Shrinkages for nonbonded distances in phosphabenzene.

\begin{tabular}{ll}
\hline \hline Distance & Shrinkage $(\AA)$ \\
\hline $\mathrm{P} \cdots \mathrm{C}_{3}$ & 0.0043 \\
$\mathrm{P} \cdots \mathrm{C}_{4}$ & 0.0063 \\
$\mathrm{P} \cdot \mathrm{H}_{7}$ & 0.0064 \\
$\mathrm{P} \cdots \mathrm{H}_{8}$ & 0.016 \\
$\mathrm{P} \cdots \mathrm{H}_{9}$ & 0.020 \\
$\mathrm{C}_{2} \cdots \mathrm{C}_{4}$ & 0.0041 \\
$\mathrm{C}_{3} \cdots \mathrm{C}_{5}$ & 0.0040 \\
$\mathrm{C}_{2} \cdots \mathrm{C}_{6}$ & 0.0020 \\
$\mathrm{C}_{2} \cdots \mathrm{C}_{5}$ & 0.0066 \\
$\mathrm{C}_{3} \cdots \mathrm{H}_{7}, \mathrm{C}_{2} \cdots \mathrm{H}_{8}$ & \\
$\mathrm{C}_{3} \cdots \mathrm{H}_{9}, \mathrm{C}_{4} \cdots \mathrm{H}_{8}$ & 0.0068 \\
$\mathrm{C}_{4} \cdots \mathrm{H}_{7}, \mathrm{C}_{2} \cdots \mathrm{H}_{9}$ & \\
$\mathrm{C}_{3} \cdots \mathrm{H}_{10}$ & 0.015 \\
$\mathrm{C}_{2} \cdots \mathrm{H}_{11}$ & 0.016 \\
$\mathrm{C}_{3} \cdots \mathrm{H}_{11}$ & 0.021 \\
$\mathrm{H}_{7} \cdots \mathrm{H}_{8}, \mathrm{H}_{8} \cdots \mathrm{H}_{9}$ & 0.0051 \\
$\mathrm{H}_{7} \cdots \mathrm{H}_{9}, \mathrm{H}_{8} \cdots \mathrm{H}_{11}$ & 0.027 \\
$\mathrm{H}_{7} \cdots \mathrm{H}_{11}$ & 0.031 \\
$\mathrm{H}_{7} \cdots \cdots \mathrm{H}_{10}$ & 0.035 \\
\hline \hline
\end{tabular}

lidity of this assumption is confirmed in later sections) and of $C_{2 v}$ symmetry.

(2) All $\mathrm{C}-\mathrm{H}$ bonds were taken to be equal.

(3) Phosphorous-hydrogen amplitudes were interrelated according to

$$
l_{\mathrm{p} \cdots \mathrm{H}_{8}}=l_{\mathrm{p} \cdots \mathrm{H}_{7}}-0.005 \AA
$$

and

$$
l_{\mathrm{p} \cdots \mathrm{H}_{9}}=l_{\mathrm{p} \cdots \mathrm{H}_{7}}-0.007 \AA .
$$

(4) Average values were given to all $\mathrm{C} \ldots \mathrm{H}$ nonbonded amplitudes and $\mathrm{H} \ldots \mathrm{H}$ nonbonded amplitudes, respectively, and $l_{\mathrm{H}} \cdots_{\mathrm{H}}$ was fixed at $0.130 \AA$.

It has been reported in some cases that inclusion of spectroscopic data can make such assumptions unnecessary. For example, in acrolein, ${ }^{19}$ propynal, ${ }^{20}$ and isobutane, ${ }^{21}$ different $\mathrm{C}-\mathrm{H}$ bond lengths can be resolved in the combined analysis. But since the microwave spectroscopic data in the present study are severely limited, the hydrogens are less well determined and no attempt was made to resolve the different $\mathrm{C}-\mathrm{H}$ bond lengths.

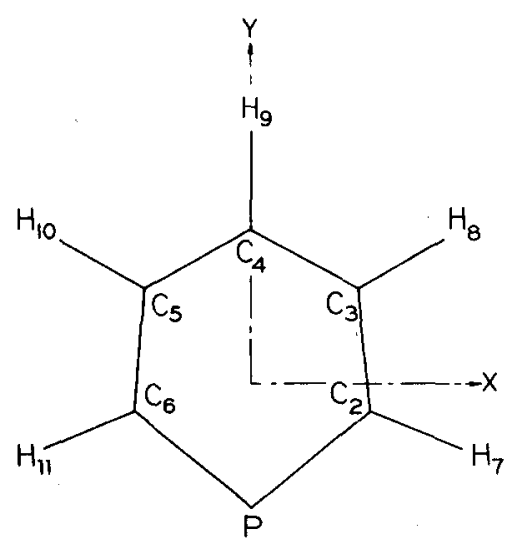

FIG. 1. Numbering of atoms and principal axes for phosphabenzene. 
A diagonal weight matrix was adopted for the diffraction intensity in the least squares analysis, with elements proportional to the square of the scattering variable $s$. This weighting, corresponding to a uniform weighting for $s M(s)$, was found to distribute the noise almost uniformly over the $s$ space.

\section{CONVERSION TO AVERAGE STRUCTURE}

It was shown in recent studies that it is advantageous to determine structures by electron diffraction and spectroscopy simultaneously where possible, and that the derived parameters from the two methods can be related rigorously to each other if proper considerations of the differences between vibrational averages are taken into account. ${ }^{22}$ For some simple molecules, structures derived from each method agreed very well when reduced to the same physical basis, the so-called "average structure" ${ }^{23}$ in the zero-point vibrational state. For more complicated molecules such as this case, phosphabenzene, a combined use of the two methods will have a definite advantage in obtaining a more complete structure determination than can be deduced from either source alone.

To reduce the parameters from the two methods to a common physical basis, a knowledge of the quadratic force field of the molecule is necessary. Since there has been no report in the literature on either the force field or the complete assignment of the vibrational frequencies of phosphabenzene, it was necessary to construct an approximate force field by extrapolating and transferring part of the interaction constants from benzene $^{24}$ and pyridine. ${ }^{18}$ A modified Urey-Bradley force field ${ }^{25}$ was used for in-plane vibrations, and for out-ofplane vibrations, a force field similar to that used by Shimanouchi ${ }^{24}$ for benzene was used. Although there were not enough assigned vibrational frequencies to check the accuracy of the force field, the force field was considered to be close enough for the present purpose, because it does produce a distribution of frequencies in the range expected for such a compound. The molecule is rigid enough ${ }^{26}$ that the $B_{0}$ to $B_{\varepsilon}$ correction (which depends on the force field mainly through the frequencies it produces) and the shrinkages (derived from the perpendicular vibrational amplitudes) are not expected to be very sensitive to the details of the force field. Another indication that the vibrational effect is reasonably well accounted for by the force field is given by the inertial defect shown in Table III. The inertial defect calculated after correction for vibrations is small and falls in magnitude (but not sign) within the range of electronic contributions to the inertial defect calculated for a series of similar aromatic compounds. ${ }^{27,28}$ The force constants and the frequencies calculated from the se force constants have been listed elsewher $e^{29}$ and are available from ASIS. ${ }^{11}$

The procedure of simultaneous least squares analysis of electron diffraction intensities and moments of inertia obtained from spectroscopy was similar to that devised by Kuchitsu et al. ${ }^{19}$ The $r_{g}$ internuclear distances which are usually reported in electron diffraction analyses were converted to $r_{\alpha}$ distances corresponding to a geometrically consistent $r_{\alpha}$ structure by the standard relation

$$
r_{\alpha}=r_{g}-K_{T}-\delta r_{\text {cent }},
$$

where $K_{T}$ is a foreshortening due to the mean square perpendicular amplitudes of vibration for the distance concerned at the temperature $T$ at which the experiment was conducted and $\delta r_{\text {cent }}$ is the centrifugal distortion due to the rotational motion of the molecule. The $r_{\alpha}$ was then extrapolated to the zero point vibrational level by

$$
r_{\alpha}^{0}=r_{\alpha}-\frac{3}{2} a\left(\left\langle\Delta z^{2}\right\rangle_{T}-\left\langle\Delta z^{2}\right\rangle_{0}\right)+K_{T}-K_{0},
$$

where $a$ is the Morse anharmonicity constant, ${ }^{14}$ and $\left\langle\Delta z^{2}\right\rangle$ is the mean square amplitude of vibration parallel to the internuclear distance concerned. The changes in angles in converting from the $r_{\alpha}$ structure to the $r_{\alpha}^{0}$ structure are assumed to be negligible.

The effective rotational constants, obtained directly from microwave spectroscopy, were converted to the zero point average rotational constants $B_{k}$, from which the $r_{\varepsilon}$ parameters can be derived. The conversion was given by the relation

$$
B_{z}-B_{0}=\Delta B_{\mathrm{vib}}+\Delta B_{\mathrm{elec}},
$$

neglecting centrifugal corrections. The vibrational correction $\Delta B_{\mathrm{vib}}$ was calculated by the formalism developed by Kuchitsu et al. ${ }^{30}$ and embodied in a program MSAV

\begin{tabular}{|c|c|c|c|c|}
\hline & $A$ & $B$ & $C$ & I. D. \\
\hline $\begin{array}{l}\text { Experimental rotational } \\
\text { constants }(\mathrm{kHz})\end{array}$ & $5113.93 \pm 0.04$ & $3505.54 \pm 0.01$ & $2079.39 \pm 0.01$ & \\
\hline $\begin{array}{l}\text { Experimental effective moments } \\
\text { of inertia (amu } \AA^{2} \text { ) }\end{array}$ & 98.8234 & 144.1649 & 243.0405 & 0.0522 \\
\hline Vibrational correction (amu $\AA^{2}$ ) & 0.0277 & 0.0681 & 0.0334 & \\
\hline $\begin{array}{l}\text { Average moments of inertia } \\
\left(\mathrm{amu} \AA^{2}\right)\end{array}$ & 98.8511 & 144.2330 & 243.0739 & -0.0102 \\
\hline $\begin{array}{l}\text { Average moments of inertia } \\
\text { calculated from derived } \\
\text { structure model III in } \\
\text { Table IV. }\end{array}$ & 98.8506 & 144.2274 & 243.0780 & \\
\hline
\end{tabular}

TABLE III. Experimental rotational constants, comparison of experimental and calculated moments of inertia, and inertial defects (I. D. ). 
written by Hilderbrandt. The electronic correction $\Delta B_{\text {elec }}$, which may be appreciable in molecules with an extensive $\pi$-electron system, was roughly estimated by the method suggested by Oka and Morino $^{27}$ and found to influence the structure negligibly.

One of the three principal moments of inertia being a dependent quantity, only $I_{b}$ and $I_{c}$ were chosen for use as independent observations. Their experimental values and various corrections are listed in Table III. Two sets of relative moments of inertia to diffraction intensity weighting schemes were used, one with extremely heavy weighting on the moments of intertia, i.e., $1 \times 10^{4}$ for each moment to unit weight for each intensity point, the second with the relative weight of 10 to 1 , which is the value corresponding to the ratio of the relative physical uncertainties.

The scale factor ${ }^{31}$ in the electron diffraction experiment, which relates to the camera distance and the wavelength of the incident electron, was not varied in the beginning of the least squares analysis, nor was it necessary to let it vary, because the results from both experiments are compatible with each other.

\section{RESULTS}

\section{A. From electron diffraction data alone}

The experimental and best calculated molecular intensities $s M(s)$ are compared in Fig. 2. The experimental radial distribution function is shown in Fig. 3. Severe overlapping can be seen to occur between $\mathrm{P} \ldots \mathrm{C}_{3}$, $\mathrm{C}_{2} \ldots \mathrm{C}_{6}$, and $\mathrm{C}_{2} \ldots \mathrm{C}_{5}$ distances, and also between $\mathrm{C}_{2} \ldots \mathrm{C}_{4}$ and $\mathrm{C}_{3} \ldots \mathrm{C}_{5}$ distances plus some nonbonded distances involving hydrogen. Therefore high correlations between some parameters such as the two kinds of $\mathrm{C}-\mathrm{C}$ bonds and the ring angles were expected, as is confirmed in the correlation matrix. Good agreement between the experimental and theoretical radial distribution functions was found, except at about $1.55 \AA$. Since the discrepancy occurred at a position characteristic of a carbon-carbon single bond, it was suspected that some solvent containing carbon-carbon single bonds might have been present in a small amount in the sample. Because of its relatively high volatility compared with phosphabenzene, such an impurity would be expected to show up most strongly in the $21 \mathrm{~cm} R^{3}$ sector

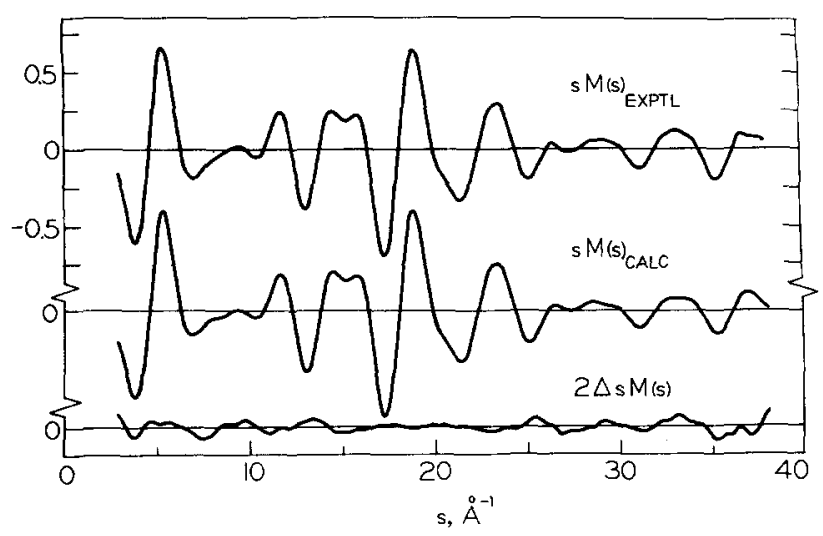

EIG. 2. Experimental and calculated molecular intensity functions for phosphabenzene.

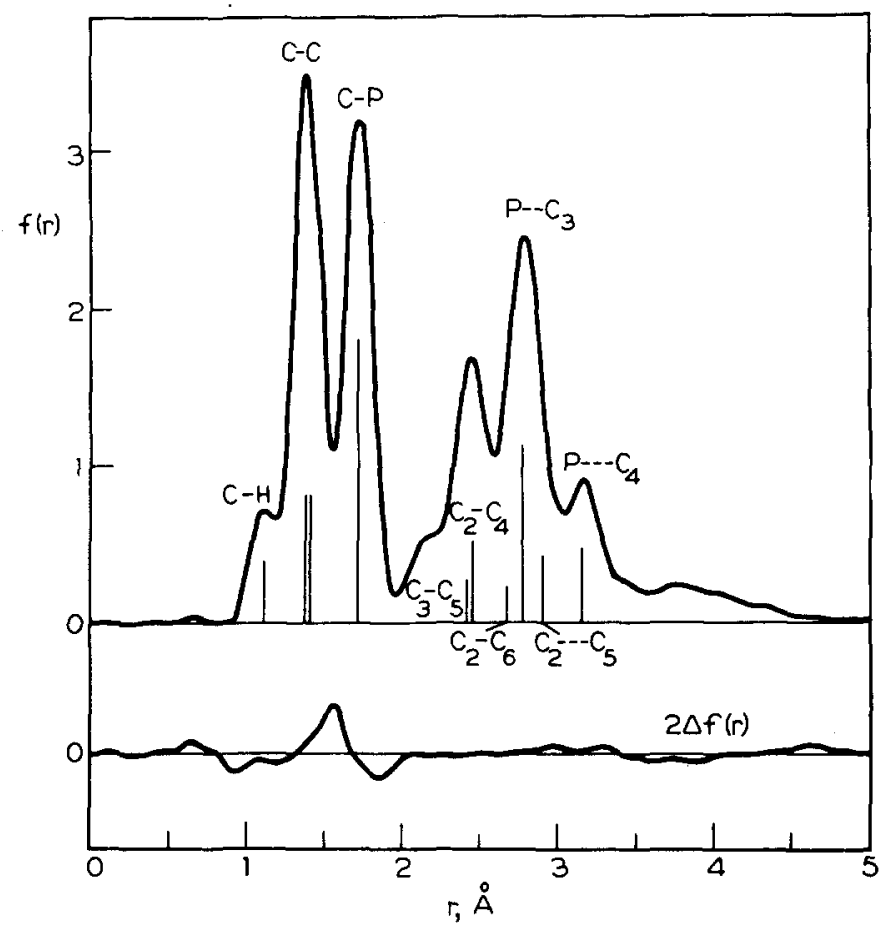

FIG. 3. Experimental radial distribution function for phosphabenzene. $\Delta f(r)=f(r)_{\text {expt }}-f(r)_{\text {calc }}$.

patterns which were taken first. An examination of the residuals in the reduced intensities did show a rather systematic pattern in $s M(s)$ between $s=5 \AA^{-1}$ to $s=18$ $\AA^{-1}$, the range spanned by the above-mentioned pattern. From the experimental procedure of synthesis and isolation of the sample, the most likely candidates were $n$-pentane and diethyl ether. A correction corresponding to a $4.3 \% n$-pentane contribution to the experimental intensity was tried to determine the effect of the possible contamination on the derived structure. The percentage of impurity was chosen to reproduce, approximately, the observed magnitudes of the residuals in the radial distribution function. Corrections were made by subtracting from the experimental leveled intensity $I_{0}(s)$ the contribution to the intensity from the impurity using appropriate theoretical expressions and the known structure of $n$-pentane. ${ }^{32}$ Least squares analysis of the corrected intensity showed that the correction does have the expected effect of increasing very slightly the C-P bond length and decreasing the $\mathrm{C}_{2}-\mathrm{C}_{3}$ bond length. Details are shown in Table IV along with the structure derived from the original intensity. None of these changes is as large as the experimental uncertainties estimated for the derived parameters. A later analysis combining diffraction and spectroscopic data with extremely heavy weight on the latter data (approximately $1 \times 10^{4}$ for each moment of inertia to unit weight for each intensity point) resulted in practically the same structure. It can be regarded as an indication that the structure derived from the original intensity data was not seriously distorted by the possible existence of impurities.

The degree of correlation between observations was estimated from their residuals in the least squares treatment. The $\gamma$ factor, which is defined according to ${ }^{33}$

$$
\rho\left(s_{i}, s_{j}\right)=\left\langle V_{i} V_{j}\right\rangle /\left(\left\langle V_{i}^{2}\right\rangle\left\langle V_{j}^{2}\right\rangle\right)^{1 / 2}
$$


TABLE IV. Parameters derived from least squares analysis for phosphabenzene, and comparison with amplitudes of vibration calculated from approximate force field.

\begin{tabular}{|c|c|c|c|c|c|c|}
\hline Parameter & $\begin{array}{l}\text { Model I } \\
\text { (E.D.) }\end{array}$ & $\begin{array}{l}\text { Model } \\
\mathrm{II}^{\mathrm{a}, \mathrm{b}} \\
\text { (E. D. ) }\end{array}$ & $\begin{array}{l}\text { Model III } \\
\text { (E.D. + SP) }\end{array}$ & $\begin{array}{l}r_{z} \\
\text { structure } \\
\text { from III }\end{array}$ & $r_{g}-r_{z}^{c}$ & $\begin{array}{l}\text { Calculated } \\
\text { amplitude of } \\
\text { vibration }\end{array}$ \\
\hline$r_{\mathrm{C}-\mathrm{H}}(\mathrm{av})$ & $1.120 \pm 0.015^{\mathrm{d}}$ & 1.125 & $1.124 \pm 0.015$ & 1.107 & 0.0178 & \\
\hline$r_{\mathrm{C}-\mathrm{p}}$ & $1.732 \pm 0.003$ & 1.733 & $1.733 \pm 0.003$ & 1.730 & 0.0026 & \\
\hline$r_{\mathrm{C}_{2}-\mathrm{C}_{3}}$ & $1.413 \pm 0.051$ & 1.411 & $1.413 \pm 0.010$ & 1.409 & 0.0038 & \\
\hline$r_{\mathrm{C}_{3}-\mathrm{C}_{4}}$ & $1.384 \pm 0.056$ & 1.384 & $1.384 \pm 0.012$ & 1.380 & 0.0037 & \\
\hline$\overline{\boldsymbol{r}}_{(C-C)}$ & $1.398 \pm 0.003$ & $1.397_{7}$ & $1.399 \pm 0.003$ & $1.395_{0}$ & 0.0038 & \\
\hline$\Delta r_{(C-C)}$ & $0.029 \pm 0.098$ & 0.027 & $0.029 \pm 0.023$ & 0.029 & & \\
\hline$r_{\mathrm{P} \cdot \cdot \mathrm{C} 3}$ & $2.782 \pm 0.007$ & 2.782 & $2.783 \pm 0.006$ & 2.781 & 0.0022 & \\
\hline$r_{\mathrm{P}} \ldots \mathrm{c}_{4}$ & $3.167 \pm 0.009$ & 3.166 & $3.166 \pm 0.005$ & 3.164 & 0.0025 & \\
\hline$r_{\mathrm{C}_{2} \cdot \mathrm{c}_{6}}$ & $2.672 \pm 0.033$ & 2.672 & $2.675 \pm 0.006$ & 2.672 & 0.0028 & \\
\hline$r_{\mathrm{C}_{2} \cdot \mathrm{C}_{4}}$ & $2.462 \pm 0.029$ & 2.460 & $2.462 \pm 0.007$ & 2.459 & 0.0027 & \\
\hline$r_{C_{3}} \cdot c_{5}$ & $2.423 \pm 0.083$ & 2.424 & $2.427 \pm 0.024$ & 2.424 & 0.0026 & \\
\hline$r_{\mathrm{C}_{2}} \cdots \mathrm{C}_{5}$ & $2.908 \pm 0.006$ & 2.908 & $2.911 \pm 0.006$ & 2.909 & 0.0021 & \\
\hline $4 \mathrm{CPC}$ & $101.0^{\circ} \pm 1.8^{\circ}$ & $101.0^{\circ}$ & $101.13^{\circ} \pm 0.3^{\circ}$ & $101.13^{\circ}$ & & \\
\hline$\Varangle \mathrm{PCC}$ & $124.4_{5}^{\circ} \pm 3.3^{\circ}$ & $124.5^{\circ}$ & $124.39^{\circ} \pm 0.6_{8}^{\circ}$ & $124.39^{\circ}$ & & \\
\hline$\Varangle \mathrm{C}_{2} \mathrm{C}_{3} \mathrm{C}_{4}$ & $123.7_{6}^{\circ} \pm 12.7^{\circ}$ & $123.7^{\circ}$ & $123.66^{\circ} \pm 0.7_{8}^{\circ}$ & $123.66^{\circ}$ & & \\
\hline$\Varangle \mathrm{C}_{3} \mathrm{C}_{4} \mathrm{C}_{5}$ & $122.5_{3}^{\circ} \pm 3.6^{\circ}$ & $122.6_{3}^{\circ}$ & $122.79^{\circ} \pm 0.7_{6}^{\circ}$ & $122.79^{\circ}$ & & \\
\hline$\star \mathrm{PCH}$ & $117.7^{\circ} \pm 6.7^{\circ}$ & $117.7^{\circ}$ & $118.29^{\circ} \pm 1.8^{\circ}$ & $118.29^{\circ}$ & & \\
\hline$\Varangle \mathrm{C}_{2} \mathrm{C}_{3} \mathrm{H}_{8}$ & $118.1^{\circ} \pm 10.8^{\circ}$ & $118.1^{\circ}$ & $114.77^{\circ} \pm 4.8^{\circ}$ & $114.77^{\circ}$ & & \\
\hline$l_{\mathrm{C}-\mathrm{P}}$ & $0.052_{4} \pm 0.007$ & $0.052_{2}$ & $0.052_{5} \pm 0.003$ & & & 0.0453 \\
\hline$l_{\mathrm{C}-\mathrm{H}}$ & $0.074_{\eta} \pm 0.014$ & 0.077 & $0.074_{8} \pm 0.014$ & & & 0.0774 \\
\hline$l_{\mathrm{C}-\mathrm{C}}$ & $0.049_{3} \pm 0.016$ & $0.049_{3}$ & $0.049_{3} \neq 0.004$ & & & 0.047 \\
\hline$l_{\mathrm{P} \cdot \mathrm{C}_{3}}$ & $0.063 \pm 0.011$ & 0.063 & $0.063_{1} \pm 0.008$ & & & 0.053 \\
\hline$l_{\mathrm{p}} \ldots \mathrm{c}_{4}$ & $0.062_{3} \pm 0.008$ & $0.062_{3}$ & $0.062_{2} \pm 0.006$ & & & 0.0598 \\
\hline$l_{\mathrm{C} \cdot \cdot \mathrm{C}}$ & $0.060 \pm 0.019$ & $0.060_{6}$ & $0.060_{5} \pm 0.007$ & & & 0.0548 \\
\hline$l_{\mathrm{C}_{2} \cdots \mathrm{C}_{6}}$ & $0.068_{5} \pm 0.04$ & $0.068_{5}$ & $0.068_{5} \pm 0.032$ & & & 0.0605 \\
\hline$l_{\mathrm{C} \ldots \mathrm{C}}$ & $0.080 \pm 0.025$ & 0.080 & $0.080 \pm 0.018$ & & & 0.0632 \\
\hline$l_{\mathrm{P} \cdot \cdot \mathrm{H} 7}$ & $0.105 \pm 0.04$ & 0.099 & $0.105 \pm 0.032$ & & & 0.101 \\
\hline$l_{\mathrm{C} \cdot{ }_{\mathrm{H}}}(\mathrm{av})$ & $0.098 \pm 0.014$ & 0.098 & $0.098 \pm 0.006$ & & & 0.097 \\
\hline$l_{\mathrm{H} \cdot \bullet \mathrm{H}}(\mathrm{av})$ & \multicolumn{3}{|c|}{0.130 (assumed) } & & & 0.130 \\
\hline$R$ & $1.039 \pm 0.047$ & 1.038 & $1.041 \pm 0.045$ & & & \\
\hline$[\sigma(I) / I]^{l}$ & $8.57 \times 10^{-4}$ & & $8.68 \times 10^{-4}$ & & & \\
\hline
\end{tabular}

${ }^{2}$ Distances (except in column 4 ) and amplitudes are $r_{g} s$ and $l_{s} s$, respectively, in $\AA$; angles are in $r_{\alpha}$ structure in degrees; index of resolution $R$ is dimensionless.

bodel II corresponds to least squares result from diffraction intensity assuming the presence of $4.3 \% n$-pentane in the sample. No separate error estimate was done for this model, presumably errors are almost the same as in Column 1. Models I and III correspond to the least squares results from the original diffraction intensity.

${ }^{\circ}$ Calculated from the approximate vibrational force field given in Tables II and III in the ASIS listing, using Eq. (4), with the parallel and perpendicular mean square amplitudes calculated from program MSAV.

${ }^{d}$ All estimated uncertainties include both systematic and random errors. Systematic errors are estimated to be 2 parts per 10000 in wavelength measurement, 3 parts per 10000 in camera distance measurement, and 2 parts per 10000 in the radial measurement in microphotometer scanning. The uncertainties listed here correspond to $2.5 \sigma$, where $\sigma$ is the standard deviation.

Uncertainties in this column concerning angles do not include any allowance for uncertainties in the shrinkage corrections used.

${ }^{i}$ Fractional weighted standard deviation of electron diffraction intensities.

$$
=e^{-r\left|s_{i}-s_{j}\right|}
$$

in the intensity correlation function, was estimated to be $1.0 \AA$, based on the short range correlations between data. At larger ranges $\left(\Delta s>0.6 \AA^{-1}\right)$ the exponential behavior was no longer followed. A value of $1 \AA$ is similar to the values obtained from other experiments. ${ }^{34}$ This value was later used in the estimation of experimental uncertainties in the "bona fide" error matrix treatment.

\section{B. Combined analysis of diffraction and spectroscopic data}

It was observed from the combined least squares analysis of diffraction and spectroscopic data that the structural parameters and vibrational amplitudes derived were practically the same as those obtained from diffraction data alone, except for a small change in the $\mathrm{CCH}$ angle, which is extremely insensitive to the experimental diffraction data. It was also observed that different relative weightings of spectroscopic data to diffraction data did not give different values for the parameters. It was expected that the correlation patte ms between parameters would change with changes in relative weighting, but in this case, the change was not large enough to be worthy of separate discussion. The standard errors for the moments of inertia calculated from the model derived from the combined analysis were pleasingly low for both 
weightings, being well within the uncertainties associated with the experimental data, thus satisfying the empirical criterion of assigning weights used by Kuchitsu et al. ${ }^{19}$ For the sake of simplicity, only the result from the second choice of weighting is presented.

\section{DISCUSSION OF ERRORS}

For the estimation of uncertainties in the electron diffraction analysis, both the "zero order error matrix," which is defined as

$$
\mathbf{M}_{x}^{0}=\mathbf{B}^{-1}\left(\mathbf{V}^{\prime} \mathbf{W ~ V}\right) /(n-m) \text {, }
$$

where $B, V$, and $W$ are the information matrix, residual matrix, and the weight matrix, respectively, ${ }^{35}$ and $n$ and $m$ are the number of observations and number of independent parameters, and the "bona fide error matrix," 36 $\mathbf{M}_{x}^{w}$, the latter of which takes into account correlation between experimental data according to the model of noise implied by Eq. (6), were calculated. The correlation matrices showed that several parameters are very highly correlated, especially strong correlations being observed between the $\mathrm{C}-\mathrm{C}$ bond lengths and all the angular parameters and the $\mathrm{C}-\mathrm{C}$ and $\mathrm{C} \ldots \mathrm{C}$ amplitudes. This contributes greatly to the high uncertainties for these parameters. A comparison of the elements of the two matrices $\mathrm{M}_{x}^{0}$ and $\mathbf{M}_{x}^{w}$ showed that the simplified relations derived in Ref. 36 hold quite well for angles, distances, and corresponding amplitudes not severely affected by geometric constraints, but do not agree for other parameters. Especially large deviations between the results of the two methods of calculation were observed in the $\mathrm{C}-\mathrm{C}$ bond lengths, the PCC bond angle and the $\mathrm{C}-\mathrm{C}$ amplitude. The values calculated directly from the two matrices were much lower than those calculated from Eqs. (20)-(22) of Ref. 36, which can be interpreted as indicating that the positions of atoms $\mathrm{C}_{3}$ and $\mathrm{C}_{5}$, and hence the values of the $\mathrm{C}-\mathrm{C}$ bond lengths and the PCC angle, were largely determined from geometric constraints via the longer nonbonded distances.

The treatment for the bona fide error matrix tends to give a more optimistic error estimate for larger internuclear distances and their corresponding amplitudes of vibration than does the "zero order error matrix," which is correct only for uncorrelated noise. Since this result appears to be a physically unreasonable consequence of the Markovian model of noise in the bona fide treatment, it seems more realistic to choose the larger of the two estimates as the experimental uncertainties. It is worth noting that a common treatment of electron diffraction errors makes use of nondiagonal weight matrices to take data correlation into account. This method generally gives results identical to those from the bona fide error matrix. It is reasonable to suspect, then, that the nondiagonal treatment may also be overoptimistic for the longer molecular distances.

Although the determination of the individual $\mathrm{C}-\mathrm{C}$ bond lengths was associated with large uncertainties, their mean value, which is also reported in Table IV, was well determined. It appears that the two $\mathrm{C}-\mathrm{C}$ bonds are not of equal length, $C_{2}-C_{3}$ being longer than $C_{3}-C_{4}$ by 0.029 $\AA$. However, in addition to strong correlations with a
TABLE V. Comparison of the diagonal elements ${ }^{2}$ of various error matrices for phosphabenzene.

\begin{tabular}{|c|c|c|c|c|c|}
\hline Parameter & $\mathbf{M}_{x}^{0 b}$ & $\mathrm{M}_{x}^{w c}$ & $\begin{array}{l}\mathrm{M}_{x}^{w c} \\
(\mathrm{ED}+\mathrm{MW})\end{array}$ & $\mathbf{M}_{x}^{a \mathrm{~d}}$ & $\mathbf{M}_{x}^{a b d}$ \\
\hline$r_{\mathrm{C}-\mathrm{P}}$ & 0.00077 & 0,00098 & 0.00098 & 0.00084 & 0.00077 \\
\hline$r_{\mathrm{C}_{2}-\mathrm{C}_{3}}$ & 0.021 & 0.019 & 0.0042 & 0.022 & 0.021 \\
\hline $\bar{\gamma}_{\mathrm{C}-\mathrm{C}}$ & 0.00082 & 0.00099 & 0.0008 & 0.00084 & 0.00077 \\
\hline$\Delta r_{\mathrm{C}-\mathrm{C}}$ & 0.042 & 0.038 & 0.0091 & 0.043 & 0.042 \\
\hline$r_{\mathrm{p}} \ldots \mathrm{c}_{4}$ & 0.0037 & 0.0030 & 0.0022 & 0,0037 & 0.0037 \\
\hline$r_{\mathrm{C}-\mathrm{H}}$ & 0.0037 & 0.0062 & 0.006 & 0.0043 & 0.0039 \\
\hline$\Varangle C P C$ & 0.013 & 0.012 & 0.002 & 0,014 & 0.014 \\
\hline$\Varangle P C C$ & 0.023 & 0.022 & 0.0047 & 0.024 & 0.024 \\
\hline$\Varangle \mathrm{C}_{2} \mathrm{C}_{3} \mathrm{C}_{4}$ & 0.019 & 0.017 & 0.0054 & 0.019 & 0.018 \\
\hline$\times \mathrm{PCH}$ & 0.047 & 0.045 & 0.013 & 0.050 & 0.048 \\
\hline$\star \mathrm{C}_{2} \mathrm{C}_{3} \mathrm{H}$ & 0.076 & 0.065 & 0.034 & 0.078 & 0.077 \\
\hline$l_{\mathrm{C}-\mathrm{P}}$ & 0.00087 & 0.0019 & 0.0011 & 0.37 & 0.002 \\
\hline$l_{\mathrm{p}} \cdot \mathrm{C}_{3}$ & 0.0045 & 0.0042 & 0.0032 & 0.31 & 0.0048 \\
\hline$l_{\mathrm{P}} \cdots \mathrm{c}_{4}$ & 0.0032 & 0.0026 & 0.0025 & 0.31 & 0.0037 \\
\hline$l_{\mathrm{P} \cdot \mathrm{H}_{\mathrm{H}}}$ & 0.016 & 0.013 & 0.013 & 0.20 & 0.016 \\
\hline$l_{\mathrm{C} \cdot \mathrm{H}}$ & 0.0054 & 0.0056 & 0.0055 & 0.19 & 0.0056 \\
\hline$l_{\mathrm{C}-\mathrm{C}}$ & 0.0066 & 0.0064 & 0.0017 & 0.39 & 0.0072 \\
\hline$l_{\mathrm{C}} \cdot \cdot \mathrm{C}$ & 0.0077 & 0.0072 & 0.0029 & 0.32 & 0.0081 \\
\hline$l_{c_{2} \cdot \cdot c_{0}}$ & 0.016 & 0.015 & 0.013 & 0.29 & 0.016 \\
\hline$l_{\mathrm{C}} \ldots \mathrm{C}$ & 0.010 & 0.0089 & 0.0071 & 0.24 & 0.010 \\
\hline$l_{\mathrm{C}-\mathrm{H}}$ & 0.0033 & 0.0056 & 0.0056 & 0.26 & 0.0037 \\
\hline$R$ & 0.014 & 0.019 & 0.018 & 34.28 & 0.104 \\
\hline$E_{1}^{*}$ & & & & 38.61 & 0.099 \\
\hline$E_{2}{ }^{\bullet}$ & & & & 4.92 & 0.048 \\
\hline$E_{3} \cdot$ & & & & 0.58 & 0.023 \\
\hline
\end{tabular}

${ }^{2}$ Values given here are square roots of the diagonal elements of the error matrices, i.e., the standard deviations of the corresponding parameters. Distances and amplitudes are in $\AA$, angles in radians, $R$ and $E$ 's are dimensionless.

b" "Zero order error matrix" as defined in Eq. (6).

c"Bonafide error matrix" as defined in Ref, 36. In column 3, microwave spectroscopic moments of inertia were included in the matrix of observation.

Matrices taking into account systematic errors in intensities as proposed in Ref. 37. These matrices should be compared with $\mathbf{M}_{x}^{0}$ for they neglect the correlation of data embodied in $\mathbf{M}_{x}^{w}$. 'The $E_{k}{ }^{\prime}$ 's are envelope function coefficients as defined in Ref. 37.

host of other parameters, these two closely spaced distances with exactly equal scattering powers are also susceptible to correlation with some systematic errors such as emulsion calibration, emulsion developing technique, extraneous scattering, and inaccurate scattering factors, etc., as pointed out by Bartell and Yow. ${ }^{37}$ Error matrices $\mathbf{M}_{x}^{\mathfrak{u}}$ and $\mathbf{M}_{x}^{a b}$ as defined in Ref. 37 , were computed with a four term envelope function $(k=3)$ to investigate the possible coupling of the derived parameters with systematic errors. All computations were made on the $r_{g}(1)$ basis, which was found ${ }^{37}$ to be more sensitive than $r_{g}$. The diagonal elements of these matrices are compared with those of zero order and bona fide matrices in Table $\mathrm{V}$. The resolving power of the two $\mathrm{C}-\mathrm{C}$ lengths, as reflected by $\sigma\left(\Delta r_{\mathrm{c}-\mathrm{c}}\right)$, was not inflated to any noticeable extent by the inclusion of the envelope function for either $\mathbf{M}_{x}^{a}$ or $\mathbf{M}_{x}^{a b}$, nor were the uncertainties of other geometric parameters. This shows that by taking into account nonbonded distances and contraints to achieve geometric self-consistency, the resolution of these closely spaced distances and the geometric parameters over all are not seriously affected by these systematic errors. On the other hand, the amplitudes of vibration were affected to a different extent. In $\mathbf{M}_{x}^{a}$, in which no 
limit was set for the variance of the systematic error coefficients $E_{k}$, all amplitudes were correlated with each other and with the coefficients so strongly that their uncertainties reached absurdly high values. However, by imposing a practical constraint on the limit of the variance of $E_{k}$, as revealed in $\mathbf{M}_{x}^{a b}$, the amplitudes were only slightly affected. Only $l_{C-P}$ correlated significantly with the envelope function coefficients, and all uncertainties of other amplitudes were only modestly increased. Appropriate increases in the error estimates were made for the parameters affected by the introduction of the envelope function.

In the analysis combining electron diffraction and microwave spectroscopic data, the two types of data were treated as independent observations. Thus the error matrix of observation $\mathbf{M}_{f}$ was composed of two blocks, one containing the error of observation from the electron diffraction data, treated in the same way as described in Ref. 33 for the bona fide matrix, the other block, with only diagonal elements, containing uncertainties pertaining to the spectroscopic data. The latter, in this case, arose mainly from the conversion from $B_{0}$ to $B_{\varepsilon}$, rather than experimental uncertainties in observed frequencies, and were taken to be 0.007 and 0.006 amu $\AA^{2}$, respectively, for $\sigma\left(I_{B}\right)$ and $\sigma\left(I_{C}\right)$. Then the error matrix was calculated by the relation

$$
\mathbf{M}_{x}^{w}=[n /(n-m)] \mathbf{B}^{-1} \mathbf{A}^{\prime} \mathbf{W} \mathbf{M}_{f} \mathbf{W} \mathbf{A} \mathbf{B}^{-1} \text {. }
$$

The diagonal elements of the error matrix and its correlation matrix are given in Tables $\mathrm{V}$ and VI. As has been pointed out before, ${ }^{38}$ inclusion of the moments of inertia (or rotational constants) into the analysis of diffraction intensity will often drastically change the correlation pattern between parameters. It is gratifying to find that in the combined analysis a substantial decrease of correlation between some parameters resulted, especially involving the $\mathrm{C}-\mathrm{C}$ bonds. The effect was reflected also by a fivefold decrease of $\sigma(\mathrm{C}-\mathrm{C})$ and a fourfold decrease of $\sigma\left(\Delta r_{\mathrm{C}-\mathrm{C}}\right)$. Significant decreases of the correlation among angular parameters and the higher sensitivity of the moments of inertia with respect to the angles caused the sharp drop in the uncertainties for the angles.

\section{DISCUSSION OF STRUCTURE}

The structure of phosphabenzene derived from the electron diffraction and the combined analysis is close to the perceptive guess of the structure by Kuczkowski and Ashe based on two microwave moments of inertia alone. ${ }^{3}$ Electron diffraction intensities are not very sensitive in establishing the exactness of planarity in nearly planar molecules. However, a measure of the inertial defect of a molecule should give the most definitive evidence of the planarity. ${ }^{27}$ From the agreement between the small experimental defect and the inertial defect calculated from vibrational contributions, it seems to be unequivocal that phosphabenzene is planar in its equilibrium (vibrationless) configuration.

The amplitudes of vibration derived from the least squares analysis are compared with the amplitudes calculated from the approximate force field in Table IV.

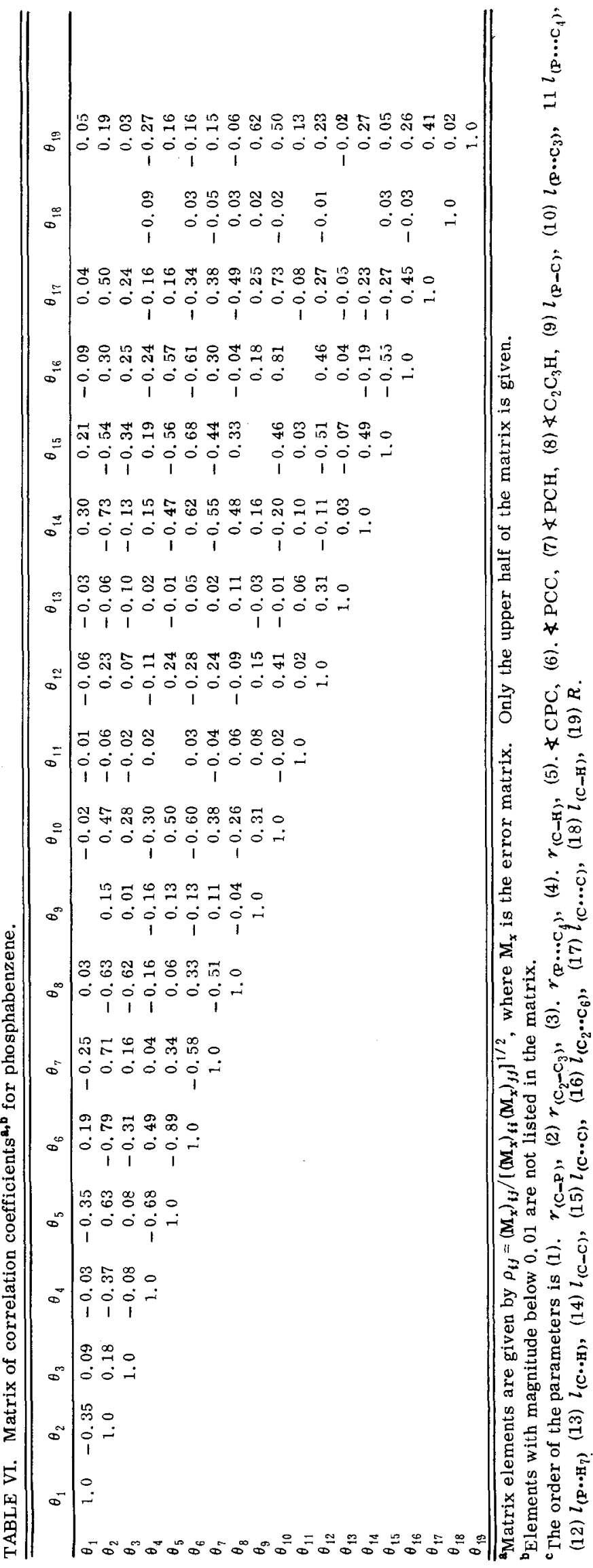


Although some experimental amplitudes are highly correlated with each other, they are in reasonably good agreement with the calculated values. The average $\mathrm{C}-\mathrm{H}$ bond length of $1.12 \pm 0.02 \AA$ is the same as corresponding lengths in other molecules to within the rather large uncertainty. The P-C bond length of $1.732 \AA$ is between typical carbon-phosphorus single bonds of about $1.85 \AA$ [for example, $1.1843 \AA$ in $\mathrm{P}\left(\mathrm{CH}_{3}\right)_{3},{ }^{39} 1.867 \AA$ in phosphirane, ${ }^{40}$ and 1.855 and $1.854 \AA$, respectively, for the endocyclic and exocyclic P-C bond lengths in 1-phenyl-4, 4-dimethoxyphosphorinan ${ }^{41}$ ] and carbon-phosphorus double bond length $s^{42}$ of about $1.66 \AA$ in pentavalent phosphorus compounds [for example, 1.661 $\AA$ in $\left(\mathrm{C}_{6} \mathrm{H}_{5}\right)_{3} \mathrm{P}$ $=\mathrm{CH}_{3},{ }^{43} 1.648 \AA$ in triphenylphosphoranylideneketen, ${ }^{44}$ and $1.677 \AA$ in triphenylphosphoranylidenethioketen ${ }^{45}$ ). This finding is consistent with the interpretation that the $\mathrm{P}-\mathrm{C}$ bond is of partial double bond character because of the delocalization of $\pi$ electrons in the system. Several $P-C$ bond lengths in phosphabenzes substituted in the $2,4,6$ positions ${ }^{46}$ and in $\lambda^{5}$-phosphorins ${ }^{47}$ have also been determined by $\mathrm{x}$-ray diffraction studies, and they are generally longer than the value obtained in the present study by $0.01-0.02 \AA$. The CPC angle and the PCC angle of $101.1^{\circ}$ and $124.5^{\circ}$, respectively, are also close to those found in substituted phosphabenzenes, leaving the three CCC angles close to $120^{\circ}$ as in benzene. The mean carbon-carbon bond length of $1.398 \AA$, is practically the same as that in benzene, which is often used as one of the criteria for aromaticity. Although the two carbon-carbon bonds have slightly different lengths, $1.413 \AA$ for $C_{2}-C_{3}$, and $1.384 \AA$ for $C_{3}-C_{4}$, they vary by a smaller amount from the benzene $\mathrm{C}-\mathrm{C}$ bond length than do the bonds in polynuclear aromatic compounds such as naphthalene and anthracene. ${ }^{48}$

The question of whether there are two different $\mathrm{C}-\mathrm{C}$ bond lengths in phosphabenzene was one of the objectives of this study, and it was interesting to find that $r_{\mathrm{C}_{2}-\mathrm{C}_{3}}$ is longer than $r_{\mathrm{C}_{3}-\mathrm{C}_{4}}$ by about $0.029 \pm 0.023 \AA(2.5 \%)$. This difference cannot be established in the analysis of electron diffraction data alone because of the high pa-

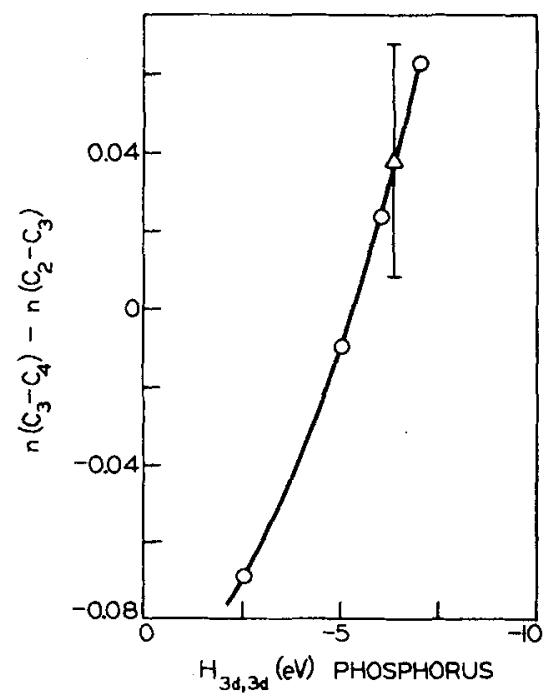

FIG. 4. Difference in electron overlap populations between the two $\mathrm{C}-\mathrm{C}$ bonds in phosphabenzene vs VOIP of phosphorus $3 d$ orbitals assumed.

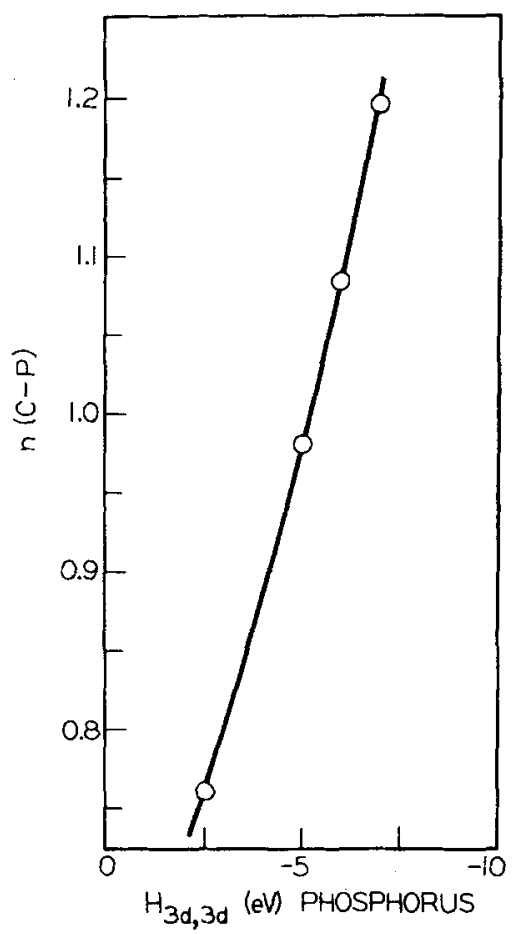

FIG. 5. Electron overlap population of $\mathrm{C}-\mathrm{P}$ bonds in phosphabenzene vs VOIP of phosphorus $3 d$ orbitals assumed.

rameter correlations in the determination. However, in refinements including the spectroscopic moments of inertia, the alleviation of the high correlations drastically reduced the uncertainty and allows this difference to be established within useful limits. P resumably this difference depends upon the extent to which the phosphorus atom participates in the $\pi$ bonding in the ring, by virtue of its $p_{r}$ and/or $d_{r}$ orbitals. In an attempt to diagnose the implications of the experimental result for $\Delta r_{c-c}$, some extended Hückel molecular orbital calculations were made, in which the molecular structure derived from the experiment was used except that the two $\mathrm{C}-\mathrm{C}$ bonds were set equal. For $2 s, 2 p, 3 s$, and $3 p$ orbitals the neutral atom VOIP of Basch, Viste, and Gray $^{49}$ were used together with the orbital exponents of Clementi and Raimondi. ${ }^{50}$ Orbital exponents of hydrogen (1s) and phosphorus ( $3 d$ ) were taken to be 1.2 and 1.1 , respectively, ${ }^{51,52}$ and $K$ was fixed at 1.75 . It was proposed to relate the observed difference in bond lengths to the difference in calculated electron overlap population using the empirical relations discussed by Hoffmann $^{53}$ and Bartell. ${ }^{52}$ It turned out that the difference in overlap population, $\Delta n(i, j)$, was highly sensitive to the contribution of the phosphorus $3 d$ orbitals as governed by the assumed value of the $3 d$ VOIP. This dependence is shown in Fig. 4. Therefore, the experimental structure provides a crude measure of the degree to which the phosphorus $3 d$ orbitals contribute to the aromaticity in the ring. If the relation ${ }^{53}$

$$
\Delta r_{i j}=\Delta n(i, j) / 1.3
$$

is applied, a value of between -6.0 and $-7.0 \mathrm{eV}$ for the phosphorus $H_{3 d, 3 d}$ is consistent with the experimental result. This value is very close to the value used in Ref. 52 , in which the $H_{3 d, 3 d}$ was scaled to simulate closely the result of $a b$ initio SCF populations. ${ }^{54}$ Furthermore, 
the results using this value imply a significant contribution of $3 d$ orbitals to the $\mathrm{P}-\mathrm{C}$ bonding as shown in the overlap populations plotted in Fig. 5. Therefore, the relative bond lengths in phosphabenzene are successfully accounted for by an EHMO calculation using a reasonable value of $H_{3 d, 3 d}$. The contribution of the phosphorus $d$ orbitals to the bonding is mainly in two of the highest occupied orbitals, the essentially nonbonding "lone pair" orbital $a_{1}$ on phosphorus, where the coefficient of $d_{x^{2}-y^{2}}$ is about 0.16 , and the out-of-plane $\pi$-bonding orbital $a_{2}$, where the coefficient of $d_{x z}$ is about 0.19 . The electron populations for these two $d$ orbitals are about 0.1 and 0.2 for $d_{x^{2}-y^{2}}$ and $d_{x z}$, respectively.

The over-all structure of phosphabenzene is consistent with the structure expected of a heterocyclic aromatic compound. The planarity, the $\mathrm{C}-\mathrm{P}$ bond length, and the average $\mathrm{C}-\mathrm{C}$ bond length give support to the proposal that the compound is aromatic. This is not surprising in view of comparisons with the analogous series of furan, thiophene, and selenophene. ${ }^{55}$ Thiophene is found to be more aromatic ${ }^{56}$ than furan even though it contains a second-row heteroatom, because of the lower electronegativity of sulfur than oxygen and probably because of the $p \pi-d \pi$ conjugation which is available in sulfur. ${ }^{52,57}$ Thus, the structure augments a growing body of experimental evidence on its stability and chemistry ${ }^{58}$ pointing to the conclusion that phosphabenzene is genuinely aromatic.

\section{ACKNOWLEDGMENTS}

This research was supported by a grant from the National Science Foundation. We thank Professor Ashe for the donation of a sample of phosphabenzene. We are pleased to acknowledge a Rackham Predoctoral Fellowship (for T. C. Wong) and a generous allowance of computing time from the Michigan Computing Center.

${ }^{1}$ A. J. Ashe III, J. Am. Chem. Soc. 93, 3293 (1971).

${ }^{2}$ H. Oehling and A. Schweig, Tetrahedron Lett. 56, 4941 (1970),

${ }^{3}$ R. L. Kuczkowski and A. J. Ashe, J. Mol. Spectrose. 42, 457 (1972).

${ }^{4}$ L. S. Khaikin and L. V. Vilkov, Russ. Chem. Rev, 41, 1060 (1972).

${ }^{5}$ L. S. Bartell, K. Kuchitsu, and R. J. deNeui, J. Chem. Phys. 35, 1211 (1961); L. S. Bartell, in Physicol Methods in Chemistry, edited by A. Weissberger and B. W. Rossiter (Interscience, New York, 1973), 4th ed.

${ }^{6}$ L. S. Bartell and H. W. Higginbotham, J. Chem. Phys. 42, 851 (1965).

${ }^{7}$ W. J. Adams and W. F. Bradford (private communication).

${ }^{8}$ R. A. Bonham and L. S. Bartell, J. Chem. Phys. 31, 703 (1959).

${ }^{9}$ L. Schäfer, A. C. Yates, and R. A. Bonham, J. Chem. Phys. 55, 3055 (1971).

${ }^{10}$ J. Karle and I. L. Karle, J. Chem. Phys. 18, 957 (1950); L. S. Bartell, D. A. Kohl, B. L. Carroll, and R. M. Gavin, Jr., J. Chem. Phys. 42, 3079 (1965).

${ }^{11}$ See NAPS document No. 02434 for pages of supplementary material. Order from ASIS / NAPS c/o Microfiche Publications, 305 E. 46th St., New York, N.Y. 10017. Remit in advance for each NAPS accession number $\$ 1.50$ for microfiche or $\$ 5.00$ for photocopies up to 30 pages, 15 for each additional page. Make checks payable to Microfiche Publications.

${ }^{12}$ L. S. Bartell, R. H. Schwendeman, and L. O. Brockway, J. Chem. Phys. 23, 1854 (1955).
${ }^{13}$ L. S. Bartell and L. O. Brockway, J. Chem. Phys. 32, 512 (1960).

${ }^{14}$ L. S. Bartell, J. Chem. Phys. 23, 1219 (1955).

${ }^{15}$ D. R. Herschbach and V. W. Laurie, J. Chem. Phys. 35, 485 (1961).

${ }^{16} \mathrm{O}$. Bastiansen and M. Traetteberg, Acta Cryst. 13, $1108(1960)$ :

Y. Morino, ibid. T. Iijima, J. Chem. Phys. 36, 1109 (1962).

${ }^{17}$ S. J. Cyvin, Molecular Vibrations and Mean Square Amplitudes (Elsevier, Amsterdam, 1968).

${ }^{18}$ Shrinkages of pyridine were calculated from a force field in which the in-plane force constants were taken from J. S. Strukl and J. L. Walters, Spectrochim. Acta 27A, 209 (1971). The out-of-plane force constants were adjusted to fit the experimental frequencies to within $1.5 \%$.

${ }^{19} \mathrm{~K}$. Kuchitsu, T. Fukuyama, and Y. Morino, J. Mol. Struct. 1, $463(1968)$.

${ }^{20}$ M. Sugie, T. Fukuyama, and K. Kuchitsu, J. Mol. Struct. 14, 333 (1972).

${ }^{21}$ R. L. Hilderbrandt and J. D. Wieser, J. Mol. Struct. 15, 27 (1973).

${ }^{22} \mathrm{~K}$. Kuchitsu, Molecular Structure and Properties, Vol. 2 of Physical Chemistry Series, One, in MTP International Review of Science, edited by G. Allen (Medical and Technical Publishing, Oxford, England, 1972), Chap. 6.

${ }^{23}$ Y. Morino, K. Kuchitsu, and T. Oka, J. Chem. Phys. 36, 1108 (1962); D. R. Herschbach and V. W. Laurie, ibid. 37, 1168 (1962).

${ }^{24} \mathrm{~J}$. Scherer and J. Overend, Spectrochim. Acta 17, 719 (1962); Y. Kakiuti and T. Shimanouchi, J. Chem. Phys. 25, 1252 (1956).

${ }^{25}$ G. Zerbi, B. Crawford, Jr., and J. Overend, J. Chem. Phys. 38, 127 (1963).

${ }^{26}$ The lowest vibrational frequencies of phosphabenzene determined from microwave spectroscopy are 290 and $325 \mathrm{~cm}^{-1}$, (see Ref. 3).

${ }^{27}$ T. Oka and Y. Morino, J. Mol. Spectrosc. 6, 472 (1961).

${ }^{28}$ W. H. Flygare and R. C. Benson, Mol. Phys. 20, 225 (1971).

${ }^{29}$ T. C. Wong, Ph. D. thesis, University of Michigan, Ann. Arbor, MI, 1974.

${ }^{30}$ K. Kuchitsu and S. Konaka, J. Chem. Phys. 45, 4342 (1966); R. L. Hilderbrandt and J. D. Wieser, ibid. 55, 4648 (1971).

${ }^{31} \mathrm{~K}$. Kuchitsu, in Molecular Structures and Vibrations, edited by S. J. Cyvin (Elsevier, Amsterdam, 1972), Chap. 12.

${ }^{32}$ R. A. Bonham, L. S. Bartell, and D. A. Kohl, J. Am. Chem. Soc. 81,4765 (1959).

${ }^{33}$ L. S. Bartell and M. G. Anashkin, J. Mol. Struct. 17, 193 (1973), and references therein.

${ }^{34}$ L. S. Bartell (unpublished); H. M. Seip, T. G. Strand, and R. Stølevik, Chem. Phys. Lett. 3, 617 (1969).

${ }^{35}$ W. C. Hamilton, Statistics in Physical Sciences (Ronald, New York, 1964).

${ }^{36}$ L. S. Bartell and M. G. Anashkin, J. Mol. Struct. 17, 193 (1973).

${ }^{37}$ L. S. Bartell and H. Yow, J. Mol. Struct. 15, 173 (1973).

${ }^{38}$ E. J. Jacob, H. B. Thompson, and L. S. Bartell, J. Mol. Struct. 8, 383 (1971); R. L. Hilderbrandt and J. D. Wieser, J. Chem. Phys. 56, 1143 (1972).

${ }^{39}$ P. S. Bryan and R. L. Kuczkowski, J. Chem. Phys. 55, 3049 (1971).

${ }^{40}$ M. T. Bowers, R. A. Beaudet, H. Goldwhite, and R. Tang, J. Am. Chem. Soc. 91, 17 (1969).

${ }^{41}$ A. T. McPhail, J. J. Breen, J. H. Somers, C. H. Steele, and L. D. Quin, Chem. Commun. 1971, 1020.

${ }^{42}$ These carbon-phosphorus double bonds involve pentavalent phosphorus instead of trivalent phsophorus, the valence state in phosphabenzene. Strictly speaking, bond lengths for different valences cannot be rigorously compared with each other. Geneune carbon-phosphorus double bonds in trivalent phosphorus are not available for comparison.

${ }^{43}$ J. C. J. Bart, J. Chem. Soc. B 1969, 350.

${ }^{44}$ J. J. Daly and P. J. Wheatly, J. Chem. Soc. A 1966, 1703. 
${ }^{45}$ J. J. Daly, J. Chem. Soc. A 1967, 1913.

${ }^{46}$ J. C. J. Bart and J. J. Daly, J. Chem. Soc. A 1970, 567; W. Fischer, E. Hellner, A. Chatzidakis, and K. Dimroth, Tetrahedron Lett. 1968, 6227.

${ }^{47}$ U. Thewalt, Angew. Chem. (Int. Ed. Engl.) 8, 769 (1969).

${ }^{48}$ D. W. J. Cruickshank and R. A. Sparks, Proc. R. Soc. A 258, 270 (1960); A. Almeningen, O. Bastiansen, and F. Dyvik, Acta Cryst. 14, 1056 (1961); G. S. Pawley and E. A. Yeats, Acta Cryst. B 25, 2009 (1969).

${ }^{49} \mathrm{H}$. Basch, A. Viste, and H. B. Gray, Theoret. Chim. Acta 3, 458 (1965).

${ }^{50} \mathrm{E}$. Clementi and D. L. Raimondi, J. Chem. Phys. 38, 2686 (1963).
${ }^{51}$ K. A. R. Mitchell, Can. J. Chem. 46, 3499 (1968).

${ }^{52}$ L. S. Bartell, L. S. Su, and H. Yow, Inorg. Chem. 9, 1903 (1970).

${ }^{53}$ R. Hoffmann, J. Chem. Phys. 39, 1397 (1963).

${ }^{54}$ D. B. Boyd and W. N. Lipscomb, J. Chem. Phys. 46, 910 (1967).

${ }^{55}$ N. N. Magdesieva, Advances in Heterocyclic Chemistry (Academic, New York, 1970), Vol. 12.

${ }^{56}$ See, for example, L. A. Paquatte, Modern Heterocyclic Chemistry (Benjamin, New York, 1968), Chap. 4.

${ }^{57}$ R. A. W. Johnstone and F. A. Mellon, J. Chem. Soc. Faraday Trans. II 69, 1155 (1973).

${ }^{58} \mathrm{~K}$. Dimroth, Fortschr. Chem. Forsch. 38, 1 (1973). 